\title{
Burden of Thyroid and Lipid disorders among Elderly Depressed Patient: A cross sectional study in Nepal
}

\author{
Rinku Gautam Joshi ${ }^{1}$, Arun Kumar Pandey ${ }^{1}$, Nidesh Sapkota ${ }^{1}$, Rajesh Kumar ${ }^{1}$, Prashant Shah ${ }^{2}$, \\ Robin Maskey ${ }^{2}$, Vivek Kattel ${ }^{2}$ \\ ${ }^{1}$ Department of Psychiatry, BP Koirala Institute of Health Sciences \\ ${ }^{2}$ Department of Internal Medicine, BP Koirala Institute of Health Sciences
}

\begin{abstract}
Background and Objectives: Depression is common psychiatric illness among geriatric population however it remains underdiagnosed and undertreated. Majority of thyroid and lipid disorders are asymptomatic or have vague symptoms unless they land with emergency medical conditions. The burden of thyroid and lipid disorder are under reported in elderly population especially depressed one. The objective of the study was to measure the burden of thyroid and lipid disorders among Elderly Depressed Patient.

Materials and methods: A hospital based cross-sectional study was conducted at BP Koirala Institute of Health Sciences, Dharan. All written consent patients more than 60 years of age with diagnosed of depression using ICD 10 criteria were screened for thyroid and lipid disorders as per hospital protocol. Those cases found to have thyroid and lipid disorders were reevaluated by physician for possibilities to rule out the false positive causes.

Results: The prevalence of thyroid disorder and dyslipidemia was $29 \%$ and $62.7 \%$ respectively among 51 elderly depressed patient. Subclinical hypothyroidism was associated with $25 \%$ of the cohort. Hypertriglyceridemia (54.9\%) was the most common form of lipid disorders followed by $47.1 \%$ increased total cholesterol level, 19.6\% increased LDL level and $13.7 \%$ low HDL level. The presence of thyroid and lipid disorders were not significantly associated with types of depression (mild, moderate, severe and recurrent).

Conclusion: Low threshold should be kept to screen subclinical hypothyroidism and dyslipidemia among geriatric depressed population due to alarming burden and adverse impact on quality of life and longevity.
\end{abstract}

Key Words: Dyslipidemia, Depression, Elderly, Thyroid Disorder.

\section{Introduction}

The average life expectancy of mankind is increasing mainly due to better nutrition, safe drinking water, improved sanitation, effective preventive public health interventions and modern medicine however this has shifted the health burden on geriatric population, mental health, non- communicable diseases, malignancy and road

Corresponding Author: Dr. Vivek Kattel, vivekkattel@ bpkihs.edu +9779852047059 traffic accidents. ${ }^{1}$ The common chronic medical conditions associated with aging are heart disease, arthritis, cataract, stroke, cancer, diabetes and subclinical hypothyroidism. ${ }^{2}$ In elderly, psychiatric illness like major depression is also common; $44 \%$ elderly in Canada and 17\% elderly in Dutch have depression. ${ }^{3,4}$ Depression is associated with increase morbidity and mortality of any other physical health problem. ${ }^{5}$ Depression remains under-diagnosed and under-treated in elder as they 
Burden of Thyroid and Lipid Disorders among Elderly...

Jour of Diab and Endo Assoc of Nepal 2018; 2 (2):(37-46)

ISSN Print 2594-3367

ISSN Online 2631-2107

have different presentations. ${ }^{5}$

The most common thyroid disorder is subclinical hypothyroidism $(\mathrm{SCH}) . \mathrm{SCH}$ is prevalent in the general population about $4-10 \%$. It occurs about $15 \%$ in elderly women and $10 \%$ in elderly men. ${ }^{6}$ $\mathrm{SCH}$ usually present with nonspecific vague symptoms and one of them could be depressive mood. Lipid disorder are usually asymptomatic unless they present with coronary artery disease, cardiovascular accidents and/or peripheral vascular disease. Hypothyroidism is one of the treatable cause for depression and/or dyslipidemia. There is an association between thyroid status and cognitive decline, depression and dementia in the elderly. ${ }^{6}$

Presence of depression in elderly increases the risk of coronary heart disease and total mortality; and also $\mathrm{SCH} .{ }^{7}$ On the other hand, prevalence of depression and $\mathrm{SCH}$ also increased with cardiovascular disease and other chronic physical diseases. ${ }^{6}$ Depression is considered to be an independent risk factor for coronary artery disease, heart failure in older hypertensive patients and mortality. ${ }^{7}$ The $\mathrm{SCH}$ is associated with cardiovascular risk factor and depression in the elderly. ${ }^{8}$

A large cross-sectional study in Colorado of 25,862 persons found that those with serum TSH concentrations of 5.1 to $10 \mathrm{mIU} / \mathrm{L}$ had higher serum cholesterol levels than those who were euthyroid. ${ }^{9}$ The Nagasaki study found a 2-fold elevation in the risk of angina and $\mathrm{MI}$ in men but not in women with $\mathrm{SCH} .{ }^{10}$ A study of patients with $\mathrm{SCH}$ who were between the ages of 70 and 79 years showed 3 -fold increased risk of congestive heart failure, but no increased risk of coronary or cerebrovascular disease or cardiovascular mortality.11 The Busselton Health Study in Australia revealed 3-fold increase in the risk of coronary artery disease and 2-fold increase in the risk of cardiovascular mortality in patients with $\mathrm{SCH} .{ }^{12}$ Women over 50 years of age with SCH with history of smoking have the highest risk for cardiovascular complications. ${ }^{13}$ A 12-year study of 3, 233 aged 65 years and older found no significant difference in the risk of coronary heart disease, cerebrovascular disease, cardiovascular death, or all-cause death between euthyroid patients and those with subclinical. ${ }^{14-18}$ Another studies suggest an increased risk of depression and panic disorder in SCH in elderly. ${ }^{19,20}$ Both the conditions are bidirectional. ${ }^{20}$

The aim of our study is to measure the burden of thyroid and lipid disorders among elderly depressed patient and correlate the relationship among these entity with severity of depression in elderly.

\section{Material and methods}

The study was approved by the institutional review board of the hospital. This is a cross- sectional, hospital based study done at BP Koirala Institute of Health Sciences (BPKIHS), Dharan, Nepal for a period of one year. All consecutive depressed patients of age 60 years and above, diagnosed on the basis of ICD - 10 criteria coming in psychiatric services of BPKIHS were included. A written informed consent was taken before enrollment of the subject. Consent was received from care taker among those who were unable to provide written consent. Considering $10 \%$ prevalence of depression among elderly we calculated the sample size of 35 with $95 \%$ confidence interval and $90 \%$ power of the study. Adding $30 \%$ as biases the final sample size was 51. Epidemiological profiles (age, sex, ethnicity, occupation, education and geographical areas, etc) were noted using a semi-structured Performa developed for the study. Relevant investigations were done and interpreted as per hospital protocol. Patient under substance use or drugs that would altered thyroid functions (given for other than thyroid disease) and lipid profile (given for other than dyslipidemia) were excluded. Those patient with deranged thyroid and lipid profile were reevaluated by physician to rule out possible cause other than thyroid or lipid disorders. Data were collected and entered in Microsoft Excel Software. Analysis was done using SPSS Software.

\section{Results}

There were 51 patients enrolled. The mean age of the patients was $66.94 \pm 7.56$. Two third of them 


\section{(0RICINALARTICLE}

were female. Majority were illiterate, married, house maker and Hindu by religion. Family history of depression was associated with $15 \%$ of the cohort. (Table 1)

Among the types of depression, recurrent depression was noted in $39.2 \%$, severe depression in $13.7 \%$, moderate depression in $39.2 \%$ and mild depression in $7.8 \%$. (Figure 1)

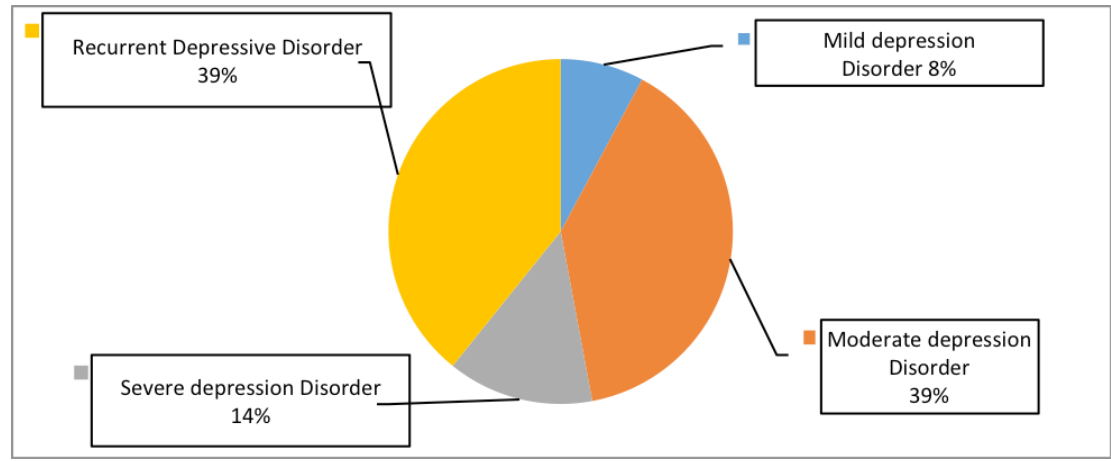

Figure 1: Types of depression

Table 1: Socio-demographic variables of the study group

\begin{tabular}{|c|c|c|c|}
\hline Characteristics & Categories & Number & Percentage \\
\hline \multirow[t]{3}{*}{ Age group in years } & $60-69$ & 35 & 68.6 \\
\hline & $70-79$ & 11 & 21.6 \\
\hline & $\geq 80$ & 5 & 9.8 \\
\hline \multicolumn{2}{|c|}{ Mean age of patient in years \pm SD $($ Min - Max $)$} & \multicolumn{2}{|c|}{$66.94 \pm 7.56(60-89)$} \\
\hline \multirow{2}{*}{ Gender } & Female & 34 & 66.7 \\
\hline & Male & 17 & 33.3 \\
\hline \multirow[t]{4}{*}{ Educational level } & Illiterate & 26 & 51.0 \\
\hline & Can read and write & 12 & 23.5 \\
\hline & Primary & 6 & 11.8 \\
\hline & SLC and above & 7 & 13.7 \\
\hline \multirow[t]{5}{*}{ Occupation } & Business & 4 & 7.8 \\
\hline & Farmer & 9 & 17.6 \\
\hline & House maker & 25 & 49.0 \\
\hline & Service & 7 & 13.7 \\
\hline & Unemployed & 6 & 11.8 \\
\hline \multirow[t]{4}{*}{ Religion } & Bhuddhist & 3 & 5.9 \\
\hline & Christian & 3 & 5.9 \\
\hline & Hindu & 43 & 84.3 \\
\hline & Kirat & 2 & 3.9 \\
\hline \multirow[t]{2}{*}{ Socio Economic Status } & Low & 19 & 37.3 \\
\hline & Middle & 32 & 62.7 \\
\hline \multirow[t]{2}{*}{ Marital Status } & Married & 42 & 82.4 \\
\hline & Widow & 9 & 17.6 \\
\hline \multirow[t]{2}{*}{ Family history } & None & 43 & 84.3 \\
\hline & Present & 8 & 15.7 \\
\hline \multicolumn{2}{|l|}{ Total } & 51 & 100.0 \\
\hline
\end{tabular}


Among 51 cases enrolled, thirty four cases $(66.7 \%)$ had other comorbidities, most commonly systemic hypertension (35.3\%), followed by type 2 Diabetes mellitus (15.7\%). Ten cases (19.6\%) had more than one multiple comorbidities. Among hypertensive cases two third were associated with isolated hypertension. Diabetes Mellitus (DM) was the second most common comorbidity accounting for 8 cases (23.53\%). (Table 2) There was no statistical significance between types of depression and the above mentioned comorbidities. (Table 3)

Table 2: Burden of other comorbidities

\begin{tabular}{|l|r|r|}
\hline Comorbidities & Frequency & Percentage \\
\hline Overall comorbidities & 34 & 66.6 \\
\hline Systemic Hypertension & 18 & 35.29 \\
\hline Diabetes mellitus & 8 & 15.68 \\
\hline Tuberculosis (treated cases) & 4 & 7.84 \\
\hline $\begin{array}{l}\text { Chronic obstructive pulmonary } \\
\text { disease }\end{array}$ & 3 & 5.88 \\
\hline Symptomatic gall stone disease & 3 & 5.88 \\
\hline Heart disease & 3 & 5.88 \\
\hline Parkinson's Disease & 2 & 3.92 \\
\hline Hearing impairment 2 & 2 & 3.92 \\
\hline
\end{tabular}

Table 3: Association between comorbidity and types of depression

\begin{tabular}{|c|c|c|c|c|c|}
\hline \multirow[t]{2}{*}{ Comorbidity } & \multicolumn{4}{|c|}{ Type of depression } & \multirow[b]{2}{*}{ Total } \\
\hline & Mild & Moderate & Severe & Recurrent & \\
\hline No & 2 & 6 & 2 & 7 & 17 \\
\hline Yes & 2 & 14 & 5 & 13 & 34 \\
\hline Total & 4 & 20 & 7 & 20 & 51 \\
\hline
\end{tabular}

Seventy one percentage of the cohort were euthyroid followed by $25 \%$ subclinical hypothyroid (SCH) and $4 \%$ hyperthyroid. (Figure 2). SCH was more prevalent among females whereas hyperthyroidism were equally distributed with gender without statistical significance. (Table 4) The relation between thyroid status and types of depression was not statistically significant. (Table 5) 


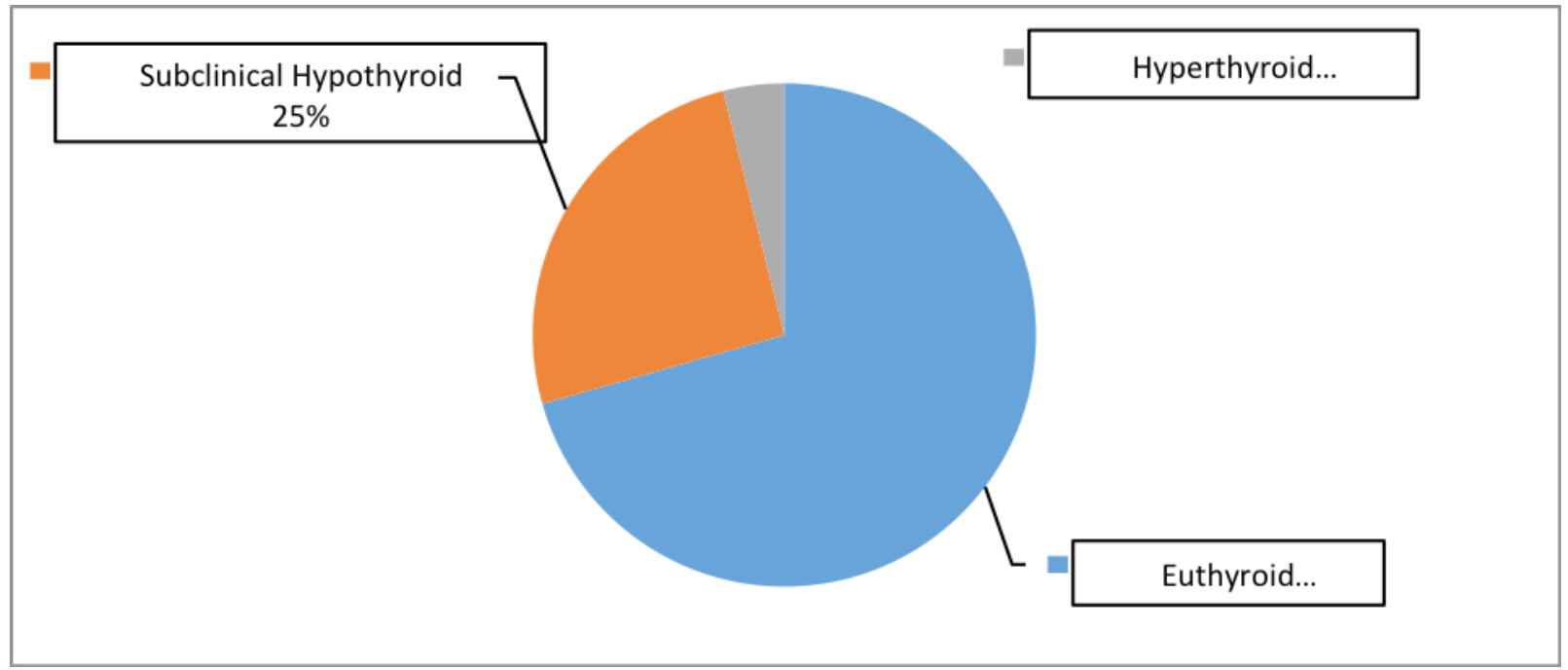

Figure 2: burden of thyroid disorder

Table 4: Thyroid profile and gender distribution

\begin{tabular}{|c|c|c|c|c|}
\hline \multirow{2}{*}{ Gender } & \multicolumn{3}{|c|}{ Thyroid Status } & \multirow{2}{*}{ Total } \\
\hline & Euthyroid & $\mathrm{SCH}$ & Hyperthyroid & \\
\hline Female & $23(67.64 \%)$ & $10(29.41 \%)$ & $1(2.94 \%)$ & $34(100 \%)$ \\
\hline \multirow[t]{2}{*}{ Male } & $13(76.47 \%)$ & $3(17.64 \%)$ & $1(5.88 \%)$ & $17(100 \%)$ \\
\hline & $36(71 \%)$ & $13(25 \%)$ & $2(4 \%)$ & $51(100 \%)$ \\
\hline
\end{tabular}

Table 5: Association between thyroid profiles and types of depression

\begin{tabular}{|c|c|c|c|c|c|}
\hline \multirow{2}{*}{$\begin{array}{l}\text { Thyroid } \\
\text { status }\end{array}$} & \multicolumn{4}{|c|}{ Type of depression } & \multirow[b]{2}{*}{ Total } \\
\hline & Mild & Moderate & Severe & Recurrent & \\
\hline Euthyroid & 2 & 17 & 6 & 11 & 36 \\
\hline $\begin{array}{l}\text { Subclinical } \\
\text { hypothyroid }\end{array}$ & 1 & 3 & 1 & 8 & 13 \\
\hline Hyperthyroid & 1 & 0 & 0 & 1 & 2 \\
\hline Total & 4 & 20 & 7 & 20 & 51 \\
\hline
\end{tabular}

The mean and median values of triglyceride and LDL was above normal limit. (Table 6) Hypertriglyceridemia $(54.9 \%)$ was the most common lipid disorders followed by hyper cholesterolemia $(47.1 \%)$, high LDL (19.6\%) and low HDL (13.8\%) levels. (Table 7) 
Table 6: Distribution of lipid profile

\begin{tabular}{|l|r|r|r|r|}
\hline & \multicolumn{1}{|c|}{$\begin{array}{c}\text { Total } \\
\text { cholesterol }\end{array}$} & Triglyceride & HDL & \multicolumn{1}{c|}{ LDL } \\
\hline Mean \pm SD & $198.26 \pm 53.02$ & $197.09 \pm 149.05$ & $49.24 \pm 14.44$ & $124.96 \pm 44.19$ \\
\hline Median & 191 & 169 & 47 & 114 \\
\hline Mode & 141 & 87 & 58 & 84 \\
\hline $\begin{array}{l}\text { Range (min }- \\
\text { max) }\end{array}$ & $218(95-313)$ & $795(53-848)$ & $66(25-91)$ & $162(66-228)$ \\
\hline
\end{tabular}

There was no statistical significance between lipid disorders and types of depression. (Table 7)

Table 7: Association between lipid disorder and types of depression.

\begin{tabular}{|c|c|c|c|c|c|c|}
\hline \multirow{2}{*}{ Lipid } & \multirow{2}{*}{ Range } & \multicolumn{4}{|c|}{ Type of depression } & \multirow{2}{*}{$\begin{array}{c}\text { Total } \\
(\%)\end{array}$} \\
\hline & & Mild & Moderate & Severe & Recurrent & \\
\hline \multirow{3}{*}{$\begin{array}{l}\text { Total } \\
\text { Cholesterol }\end{array}$} & Normal & 2 & 9 & 5 & 11 & $27(52.9)$ \\
\hline & Increased & 2 & 11 & 2 & 9 & $24(47.1)$ \\
\hline & Total & 4 & 20 & 7 & 20 & 51 \\
\hline \multicolumn{7}{|c|}{$\chi^{2}=1.51, p$ value $=0.67$} \\
\hline \multirow{3}{*}{$\begin{array}{l}\text { Triglycerides } \\
\text { TG }\end{array}$} & Normal & 1 & 11 & 5 & 6 & $23(45.1)$ \\
\hline & Increased & 3 & 9 & 2 & 14 & $28(54.9)$ \\
\hline & Total & 4 & 20 & 7 & 20 & 51 \\
\hline \multicolumn{7}{|c|}{$\chi^{2}=5.24, p$ value $=0.15$} \\
\hline \multirow{3}{*}{$\begin{array}{l}\text { High density } \\
\text { lipoproteins } \\
\text { HDL }\end{array}$} & Normal & 4 & 19 & 5 & 16 & $44(86.2)$ \\
\hline & Decreased & 0 & 1 & 2 & 4 & $7(13.8)$ \\
\hline & Total & 4 & 20 & 7 & 20 & 51 \\
\hline \multicolumn{7}{|c|}{$\chi^{2}=3.89, p$ value $=0.27$} \\
\hline \multirow{3}{*}{$\begin{array}{l}\text { Low density } \\
\text { lipoprotein } \\
\text { LDL }\end{array}$} & Normal & 2 & 17 & 6 & 16 & $41(80.4)$ \\
\hline & Increased & 2 & 3 & 1 & 4 & $10(19.6)$ \\
\hline & Total & 4 & 20 & 7 & 20 & 51 \\
\hline
\end{tabular}

\section{Discussion}

According to the classification of the old age; ${ }^{21}$ most of the cases were young old of 60 to 69 years age group comprising of $68.6 \%$, followed by the middle old of 70 to 79 years comprising $21.6 \%$ and lastly the very old more than 80 years comprising $9.8 \%$. This is similar to the age pyramid of Nepal. ${ }^{22}$

In our study, there was preponderance of female; the female to male ratio was $2: 1$. Female preponderance has been shown by other studies as well. ${ }^{23-25}$ 
Burden of Thyroid and Lipid Disorders among Elderly...

Jour of Diab and Endo Assoc of Nepal 2018; 2 (2):(37-46)

Forty nine percentage were literate which is comparable to Nepal's literacy rate of $57.4 \%$ where the female literacy rate is $46.7 \% .{ }^{26}$ As there was female preponderance most of the cases were housewife. Hindu (84.3\%) was the commonest religion which is similar to the distribution of religion in the country. ${ }^{27}$

In the 51 cases of depression, 39.2\% were recurrent. Severe, moderate and mild depression constituted $13.7 \%, 39.2 \%$ and $7.8 \%$ respectively. This is different from the study by Das BKL et al where the severe depression was the most common accounting for $36 \%{ }^{26}$

In our study, single comorbidity was present in $66.7 \%$ cases whereas $19.6 \%$ had multiple comorbidities. This is comparable to a population study where $24 \%$ aged 65 years or older; and $31.4 \%$ aged 85 years or older had multiple comorbidities. ${ }^{28}$ The prevalence of comorbidities and number of comorbid conditions increase with age. ${ }^{29}$ In this study, hypertension (35.2\%) followed by Diabetes mellitus $(15.3 \%)$ were the two most common comorbidities. This is similar to the study by Gerda G F et al where in a sample size of 4126 subjects, $57 \%$ reported hypertension, $20 \%$ diabetes, $15 \%$ coronary artery disease, $9 \%$ cancer, and 9\% cerebrovascular diseases; $29 \%$ reported no disease conditions, whereas $29 \%$ multiple comorbidities. ${ }^{30}$ Moreover, many older men and women experience a gradual decline in physical strength, gait speed, manual dexterity, memory, and cognitive skills, in the absence of a clinically manifest disease process. Coexistence of multiple such impairments complicates the diagnosis, treatment, and natural course of individual health conditions in older adults. ${ }^{31}$ In our study, the presence of comorbidity was not related to the severity of depression which is similar to the findings of Polona Selic et al where the burden of somatic comorbidity was shown to be smaller than the impact of psychosocial determinants for depression and there was no significant difference in the comorbidity in depressed and non-depressed subjects. ${ }^{32}$
Most of the patients were euthyroid (71\%) followed by subclinical hypothyroid (25\%) and hyperthyroid (4\%), but there were no cases of clinical hypothyroidism. This is similar to the study by Lokesh Jain et al where the prevalence of thyroid disorder in depression was $20 \%$ and subclinical hypothyroidism(13.3\%) was more prevalent than clinical hypothyroidism $(6.7 \%)$, but there were no cases of hyperthyroidism.23,24 A study by Vale'ria Bahdur Chueire et al showed that depression was observed in the subclinical hypothyroid patients $(49 \%)$ and suggested that mood disturbances are frequent in the elderly with elevated serum TSH levels, but they do not differ in the primary hypothyroid and the nonthyroidal sick patients.33 Benedetta Demartini et al found that subclinical hypothyroidism is associated with the presence of depressive symptoms beyond the role of possible confounding factors. ${ }^{34}$ In a study by Aeijaz U1 Noor et al, they found that major psychiatric disorders namely major depressive disorders had demonstrable changes in their thyroid functions and the prevalence of major depressive disorders was $30.77 \%$ in Sub-Clinical Hpothyroidism and 6 $\%$ in Clinical Hpothyroidism. ${ }^{35}$

In a prospective cohort study of 606 older adults, both baseline and persistent subclinical hypothyroidism were not associated with increased depressive symptoms; but results were consistent with a possible association between subclinical hyperthyroidism and increased depressive symptoms. ${ }^{36}$ In our study also, the thyroid status was not associated with increased depressive symptoms. However, in a study of younger sample (15 to 60 years) by Das BKL et al, a multiple comparison testing between the groups of the patients of mild, moderate and severe depression showed significantly high TSH levels. ${ }^{26}$

Regarding dyslipidaemia a strong risk factor for cardio and cerebrovascular disease, more than half of the cases had increased level of triglyceride $(54.9 \%)$ and similarly $52.9 \%$ had normal level of total cholesterol, but high density lipoprotein $(86.2 \%)$ and low density lipoprotein $(80.4 \%)$ were 
Burden of Thyroid and Lipid Disorders among Elderly...

Jour of Diab and Endo Assoc of Nepal 2018; 2 (2):(37-46)

in most cases within the normal range. In our study, the relation between the lipid profile and types of depression was not statistically significant. This is similar to the study by Onuegbu A.J et al where there was significant increase in plasma triglyceride in depression, irrespective of the severity of disease, and showed that plasma lipid and lipoprotein levels did not demonstrate any definite pattern with increasing level of depression in patients. ${ }^{37}$ This is in contrary to the study by Stefanos Tyrovolas et al where a considerable proportion of sample $(53.2 \%)$ had hypercholesterolemia and hypercholesterolemia was correlated with depressive symptomatology. ${ }^{38}$ Similarly, a study by Nikolaos Dimopoulos et al was done to examine the association of plasma lipid concentrations with changes in cognitive function and depressive states in elderly Greek individuals and it showed that an association existed between the plasma concentration of cholesterol and HDL and depression and/or cognitive impairment. ${ }^{39}$ In a study on elderly Finnish men $(n=470)$ by Sinikka Aijanseppa et al, it was also found that low total serum cholesterol was associated with a high amount of depressive symptoms independently of weight change or chronic disease. ${ }^{40}$ In a study by Jae-Min Kim et al, it was shown that lower highdensity lipoprotein level (but neither hypertension nor diabetes) were significantly associated with depression (independently of disability and cognitive function). ${ }^{41}$

\section{Conclusion}

Elderly depressed patient had high burden of thyroid and lipid disorder however these disorders were not associated with severity and recurrence of depressive disorders. Besides thyroid and lipid disorder these patient has higher burden of comorbidities like hypertension and diabetes. Nonspecific clinical signs and symptoms of thyroid and lipid disorder is likely to under screen these disorder at point of care. All the elderly depressed patients are recommended to be evaluated for thyroid and lipids biochemically. All the thyroid disorder in elderly patients are recommended to be evaluated for depression.

\section{Limitations}

This is a hospital based study. This is a cross sectional study among the depressed subjects. Further studies are recommended for causal and temporal associations.

Acknowledgement: We would like to acknowledge Department of biochemistry and Public health.

The author declares no conflict of interest.

\section{REFERENCES}

1. Taylor W.D. et al. Medical comorbidity in latelife depression. Int. J. Geriatr Psychiatry 2004; 19: 935-943.

2. Patten S.B., Beck C.A. et al. Long-term medical conditions and major depression: strength of association for specific conditions in the general population. Can J Psychiatry 2005; 50:195-202.

3. Canadian Institute of Health Information, 2010. Depression among seniors in residential care. Continuing Care Analysis in Brief May 2010.

4. Beekman ATF, Deeg D.J.H et al. Major and minor depression in later life: a study of prevalence and risk factors. J. Affect. Disord. 1995; 36:65-75.

5. Depression in older adults; BMJ 2011;343:d5219.

6. Demartini B, Masu A et al. Prevalence of depression in patients affected by subclinical hypothyroidism. Panminerva Med. 2010; 52:277-82.

7. Duntas LH, Biondi B. New insights into subclinical hypothyroidism and cardiovascular risk. Semin Thromb Hemost. 2011; 37:27-34.

8. Ashizawa K, Imaizumi M, Usa Tetal. Metabolic cardiovascular disease risk factors and their clustering in subclinical hypothyroidism. Clin Endocrinol (Oxf). 2010; 72:689-95.

9. Canaris GJ, Manowitz NR, Mayor G, Ridgway EC. The Colorado thyroid disease prevalence study. Arch Intern Med. 2000; 160:526-534. 
10. Imaizumi M, Akahoshi $\mathrm{M}$, Ichimaru $\mathrm{S}$ et al. Risk for ischemic heart disease and all-cause mortality in subclinical hypothyroidism. J Clin Endocrinol Metab. 2004; 89:3365-3370.

11. Rodondi N, Newman AB et al. Subclinical hypothyroidism and the risk of heart failure, other cardiovascular events, and death. Arch Intern Med. 2005; 165:2460-2466.

12. Walsh JP, Bremner AP et al. Subclinical thyroid dysfunction as a risk factor for cardiovascular disease. Arch Intern Med. 2005; 165:24672472.

13. Kahaly GJ. Cardiovascular and atherogenic aspects of subclinical hypothyroidism. Thyroid. 2000; 10:665-79.

14. Cappola AR, Fried LP et al. Thyroid status, cardiovascular risk, and mortality in older adults. JAMA. 2006; 295:1033-41.

15. Park YJ, Lee EJ et al. Subclinical hypothyroidism $(\mathrm{SCH})$ is not associated with metabolic derangement, cognitive impairment, depression or poor quality of life (QoL) in elderly subjects. Arch Gerontol Geriatr. 2010; 50:e68-73.

16. Roberts LM, Pattison H, Roalfe A, et al. Is subclinical thyroid dysfunction in the elderly associated with depression or cognitive dysfunction? Ann Intern Med. 2006; 145:57381.

17. Jorde $\mathrm{R}$, Waterloo $\mathrm{K}$, Storhaug $\mathrm{H}$, et al. Neuropsychological function and symptoms in subjects with subclinical hypothyroidism and the effect of thyroxine treatment. J Clin Endocrinol Metab. 2006; 91:145-53.

18. Gussekloo J, van Exel E, de Craen AJ, et al. Thyroid status, disability and cognitive function, and survival in old age. JAMA. 2004; 292:2591-9.

19. Joffe RT, Levitt AJ. Major depression and subclinical (grade 2) hypothyroidism. Psychoneuroendocrinology. 1992; 17:215221.

20. Haggerty JJ, Stern RA, Mason GA, et al. Subclinical hypothyroidism; a modifiable risk factor for depression? Am J Psychiatry. 1993; 150:508-510.
21. ICD - 10 DCR

22. Census 2011. Central Bureau of Statistics. Government of Nepal.

23. Lokesh Jain, Harish Arora, KK Verma, Harful Singh, Siddharth Aswal. A study of correlation between depression and hypothyroidism in female patient. Delhi Psychiatry Journal; 16(2):283-287.Charlson M, Peterson JC: Medical comorbidity and late life depression: What is known and what are the unmet needs? Biol Psychiatry 2002; 52:226-235.

24. Forman $\mathrm{DE}$, Berman $\mathrm{AD}, \mathrm{McCabe} \mathrm{CH}$, Baim DS, Wei JY. PTCA in the elderly: the "youngold" versus the "old-old". J Am Geriatr Soc. 1992; 40(1):19-22.

25. Amy L. Byers, Kristine Yaffe, Kenneth E. Covinsky, Michael B. Friedman, Martha L. Bruce. High Occurrence of Mood and Anxiety Disorders among Older Adults. The National Comorbidity Survey Replication. Arch Gen Psychiatry. 2010; 67(5):489-496. doi:10.1001/ archgenpsychiatry.2010.35.

26. Das BK 1 et al. Kathmandu University Medical Journal (2007), Vol. 5, No. 3, Issue 19, 330334.

27. http://cbs.gov.np/image/data/Population/ Monograph_vol_1_2(1-10,11-21)/ Chapter $\% 2003 \% 20 \% 20$ S o c ia $1 \% 20$ Composition\%20of\%20the\%20Population.pdf

28. Guralnik JM. Assessing the impact of comorbidity in the older population. Ann Epidemiol. 1996; 6:376-380.

29. Wolff JL, Starfield B, Anderson G. Prevalence, expenditures, and complications of multiple chronic conditions in the elderly. Arch Intern Med. 2002; 162:2269-2276.

30. Gerda G. Fillenbaum, Carl F. Pieper, Harvey Jay Cohen,Joan C. Cornoni-Huntley, and Jack M. Guralnik. Comorbidity of Five Chronic Health Conditionsin Elderly Community Residents: Determinants and Impact on Mortality.Journal o) Gerontology. 2000; 55A(2):M84-M89

31. Arun Karlamangla et al. Comorbidity in Older Adults: Nosology ofimpairment, Diseases, and Conditions. Journal of Gerontology: Medical sciences; 2007: 62A (3): 296-300. 
32. Polona Selic, Igor S vab, Janez Rifel, Danica Rotar Pavlic,Anja C erne, Michael King, Irwin Nazareth. The pattern of physical comorbidity and the psychosocial determinants of depression: a prospective cohort study on a representative sample of family practice attendees in Slovenia. Mental Health in Family Medicine 2011; 8:147-55.

33. Vale'ria Bahdur Chueire, Emanuela Torrea o Brito Silva, Eliana Perotta, Joa o Hamilton Romaldini, Laura Sterian Ward. High serum TSH levels are associated with depression in the elderly. Arch. Gerontol. Geriatr; 36 (2003): 281-288.

34. Benedetta Demartini, Rebecca Ranieri, Annamaria Masu, Valerio Selle, Silvio Scarone and Orsola Gambini. Depressive Symptoms and Major Depressive Disorder in Patients Affected by Subclinical Hypothyroidism. A Cross-sectional Study. J Nerv Ment Dis; 202: 603-607.

35. Aeijaz U1 Noor, Ruqaya Aziz, Abdul Wahid Khan, Qazi Najeeb, Ashaqullah Bhat. Hypothyroidism and Psychiatric Disorders In A Tertiary Care Hospital. EJPMR; 2(5):15111516.

36. Manuel R. Blum, Liselotte W. Wijsman, Vanessa S. Virgini, Douglas C. Bauer, Wendy P.J. den Elzen, J. Wouter Jukema, Brendan M. Buckley, Anton J.M. de Craen, Patricia M. Kearney, David J. Stott, Jacobjin Gussekloo, Rudi G.J. Westendorp, Simon P. Mooijaart, Nicolas Rodondi. Subclinical Thyroid Dysfunction and Depressive Symptoms among the Elderly: A Prospective Cohort Study. DOI: $10.1159 / 000437387$.
37. Onuegbu A.J, Agbedana E.O, Baiyewu O, Olisekodiaka M.J, Ebesunun, Adebayo K, Ayelagbe, Adegoke. Evaluation of Plasma Lipids and Lipoproteins in Nigerians Suffering From Depressive Illness. Afr. J. Biomed. Res. 2007; 10: $133-138$.

38. Stefanos Tyrovolas, Christos Lionis, Akis Zeimbekis, Vassiliki Bountziouka, Mary Micheli, Alexia Katsarou, Natassa Papairakleous, George Metallinos, Kornilia Makri, Evangelos Polychronopoulos, Demosthenes B Panagiotakos Increased body mass and depressive symptomatology are associated with hypercholesterolemia, among elderly individuals; results from the MEDIS study. Lipids in Health and Disease.2009; 8:10.

39. Nikolaos Dimopoulos, Christina Piperi, Aristea Salonicioti, Vassiliki Psarra, Charalampos Mitsonis, Ioannis Liappas, Robert W. Lea, Anastasios Kalofoutis. Characterization of the Lipid Profile in Dementia and Depression in the Elderly. J Geriatr Psychiatry Neurol 2007; 20:138-144.

40. Sinikka Aijanseppa, Paula Kivinen, EevaLiisa Helkala, Sirkka-Liisa Kivela, Jaakko Tuomilehto3 and Aulikki Nissinen. Serum cholesterol and depressive symptoms in elderly Finnish men. Int J Geriatr Psychiatry 2002; 17: 629-634.

41. Jae-Min Kim, Robert Stewart, Il-Seon Shin, Jin-Sang Yoon. Vascular disease/risk and late-life depression in a Korean community population. British Journal of Psychiatry. 2004; 185:102-107. 